\title{
NARRATIVA DE UM PROFESSOR HUNI KUIN: A CONDIÇÃO DE SER O “OUTRO” NA ESCOLA DA CIDADE
}

\author{
Valda Inês Fontenele PESSOA ${ }^{i}$ \\ Márcia Barroso LOURETO ${ }^{\text {ii }}$
}

\begin{abstract}
RESUMO
O artigo é fruto das discussões realizadas no Laboratório de interculturalidade - Labinter/UFAC, a partir da narrativa de José Domingos Kaxinawá, originário dos povos Huni Kuin do Rio Envira - Acre. O objetivo foi analisar fatores emergidos na narrativa sobre a trajetória de formação. Problematizar os fatores de formação que proporcionaram a visibilidade ao indígena norteou a análise. A coleta da narrativa aconteceu por meio de atividades avaliativas de disciplinas universitárias, denominadas história de vida/vida escolar. Foi estabelecido diálogo com Bauman (2005), Santos (2010), Goody (2012), Veiga-Neto (2003) e Candau (2012), e com outros autores que tematizam questões indígenas; a supremacia da Língua Portuguesa e a territorialidade indígena. O indígena é o "outro" na escola da cidade, tendo que silenciar a sua cultura para se manter estudando e prosseguir nos segmentos da Educação Básica e superior.
\end{abstract}

PALAVRAS-CHAVE: Trajetória; Huni Kuin; Escola; Interculturalidade; Silenciamento.

\section{NARRATIVE OF A HUNI KUIN TEACHER: THE CONDITION OF BEING THE “OTHER” IN THE CITY SCHOOL}

\begin{abstract}
The article is the result of discussions held at the Interculturality Laboratory - Labinter / UFAC, from the narrative of José Domingos Kaxinawá, originally from the Huni Kuin peoples of the Envira River Acre. The objective was to analyze factors that emerged in the narrative about the formation trajectory. To problematize the formation factors that provided the indigenous with visibility guided the analysis. The collect of the narrative took place through evaluative activities of university subjects, called life history/school life history. Dialogue was established with Bauman (2005), Santos (2010), Goody (2012), Veiga-Neto (2003) and Candau (2012), and with other authors who address indigenous issues; the supremacy of the Portuguese language and indigenous territoriality. The indigenous is the "other" in the city school, having to silence their culture in order to keep studying and continue in the Basic and Higher Education segments.
\end{abstract}

KEYWORDS: Trajectory; Huni Kuin; School; Interculturality; Silencing.

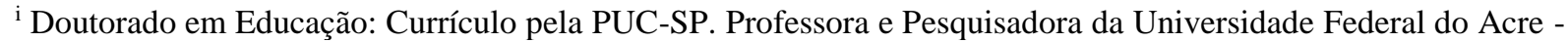
Programa de Pós-Graduação linguagem e identidade/PPGLI. E-mail: valdapessoa@ yahoo.com.br.

ii Doutoranda do Programa de Pós-Graduação Linguagem e Identidade pela UFAC. Assessora Pedagógica da Secretaria Municipal de Rio Branco-AC. E-mail: louretomarcia@gmail.com.
} 


\title{
NARRATIVA DE UN PROFESOR HUNI KUNI: LA CONDICIÓN DE SER EL “OTRO” EN
} LA ESCUELA DE LA CIUDAD

\begin{abstract}
RESUMEN
El artículo es fruto de las discusiones realizadas en el Laboratorio de interculturalidad - Labinter/Ufac, a partir de la narrativa de José Domingos Kaxinawá, originario de los pueblos Huni Kuin del Río Envira - Acre. El objetivo fue analizar factores emergidos en la narrativa sobre la trayectoria de formación. Problematizar los factores de formación que proporcionaron la visibilidad al indígena norteó el análisis. La coleta de la narrativa sucedió a través de actividades evaluativas de asignaturas universitarias, nombradas historia de vida/vida escolar. Fue establecido diálogo con Bauman (2005), Santos (2010), Goody (2012), Veiga-Neto (2003) y Candau (2012), y con otros autores que tematizan cuestiones indígenas; la supremacía de la Lengua Portuguesa y la territorialidad indígena. El indígena es el "otro" en la escuela de la ciudad, teniendo que silenciar su cultura para mantenerse estudiando y proseguir en los segmentos de la Educación Básica y superior.
\end{abstract}

PALABRAS CLAVE: Trayectoria; Huni Kuin; Escuela; Interculturalidad; Silenciamiento.

\section{INTRODUÇÃO}

Nos anos de 2016 e 2017, ministramos dois componentes curriculares denominados Estágio Supervisionado II; Infância e Pedagogia, no Curso de Graduação em Pedagogia, no município de Santa Rosa do Purus-AC, desenvolvido pela Universidade Federal do Acre, por meio do Plano Nacional de Formação de Professores da Educação Básica (PARFOR), na modalidade presencial. Com as inter-relações na turma, o caminho foi aberto para conversas com os indígenas, no decorrer das aulas e fora delas. A narrativa da qual se constitui este artigo, está ancorada em dois trabalhos acadêmicos, relacionados à história de vida/vida escolar de José Domingos Kaxinawa, aluno e originário dos povos Huni Kuin e nas percepções ocorridas durante as aulas. Os Kaxinawá se autodenominam Huni Kuin e vivem em doze terras indígenas, situadas nos Rios Breu, Jordão, Tarauacá, Murú, Humaitá, Envira e Purus. A língua originária desse povo é o Hãtxa Kui, do tronco linguístico pertencente à língua pano.

José Domingos Kaxinawá, além de ser uma liderança do seu povo, é originário de uma das primeiras famílias que chegou à região e que goza de respeitabilidade com os Huni Kuin. O caminho percorrido pela família de José Domingos, que se deslocou das terras do Rio Envira para se fixar nas terras do Purus é relevante, não apenas pelo protagonismo da narrativa que se quer evidenciar, mas também pelos fatores educacionais que emergem da trajetória de estudante e profissional da educação. 
Em 2017, José Domingos Kaxinawá tinha 58 anos de idade, com larga experiência educacional com o seu povo. Atualmente, é professor contratado para ministrar aulas em sua comunidade Huni Kuin, situada nas proximidades do Rio Purus. Zé Domingos, como era comumente chamado pelos colegas de sala de aula da graduação, integrava o grupo de onze alunos indígenas de uma turma composta de vinte discentes. Esse percentual significativo de indígenas matriculados no curso de graduação, pouco representou para alteração do desenho curricular, desenvolvido naquele município. O PARFOR, ao qual o curso estava vinculado, faz parte de uma política pública de formação de professores, que estende os cursos de licenciaturas dos campi das universidades públicas brasileiras para outras localidades do estado, desprovidas de instituição de ensino superior. A partir desse contexto, e também pelo que se apresentou na turma de Santa Rosa do Purus, entendemos ser relevantes as questões emergidas daquele espaço para pensar a formação de professores e diferença.

Nas oportunidades oriundas desse cotidiano do fazer pedagógico, ressaltavam dificuldades enfrentadas pelos indígenas naquele espaço, no qual imperava a Língua Portuguesa, a cultura científica predominante do campo educacional e a cultura dos alunos não indígenas. Apesar de ver-nos impotentes diante daquele contexto, cuja programação curricular contemplava conteúdos a serem trabalhados de forma breve e intensa, não passou despercebido ao olhar a invisibilidade dos indígenas naquele universo de formação, embora o contingente de alunos desse grupo social fosse representativo.

O comprometimento com a subjetividade do alunado, sobretudo daqueles que estão à margem, permitiu-nos enxergar, dentre as diversas particularidades, as diferentes visões de mundo que os envolviam, e, mais que isso, a tentativa de compreender os motivos que faziam com que o aluno José Domingos tivesse destaque, dentre os demais alunos indígenas que ali se encontravam. Quando esse aluno, Huni Kuin, era convidado a se pronunciar sobre pontos relevantes de alguma temática, percebíamos que a atenção dos demais se voltava respeitosamente para ele, pela forma segura e articulada dos seus argumentos. Porém, essa não era a realidade observável em muitas outras situações, em que a oratória estava sob a responsabilidade de outro indígena. Nessas oportunidades, sempre ocorriam interrupções por parte de alunos não indígenas, com argumentos de querer ajudar o colega, a deixar mais clara a fala daquele que no momento se expressava, insinuando ter potencial maior de explicação sobre a temática que se discutia na ocasião. 
Essa relação tensionada e velada entre indígenas e não indígenas, nesse espaço de formação, foi nos mobilizando a entrar nessa seara, nos colocando questões sobre essa convivência, aparentemente de submissão de um grupo sobre outro. Para este artigo, formulamos duas indagações: quais fatores teriam sido determinantes para a visibilidade conquistada por José Domingos no ambiente escolar? Quais experiências de vida escolar potencializaram José Domingos, apesar da carga preconceituosa e de exclusão que foi levado a conviver?

Tais inquietações foram mobilizadoras para buscar aproximação mais sistemática com José Domingos, para além do espaço da sala de aula e percorrer a sua trajetória de vida, a partir de conversas informais, nas quais instigávamos que narrasse episódios considerados relevantes para o seu desenvolvimento como pessoa e profissional da educação. Nesse percurso, sua trajetória escolar foi evidenciada, trazendo importantes aspectos da história do povo Huni kuin em Santa Rosa do Purus e, concomitantemente, a compreensão de aspectos que faziam com que os colegas de turma concedessem um olhar incomum e diferenciado a José Domingos, naquele contexto acadêmico.

Foi no transitar pelas águas dos Rios Envira ao Purus, deixando para trás o território de origem, na busca de outros espaços, territórios e mundos, que se desenham e se manifestam, a partir de outras linguagens e sentidos, a trajetória dos povos Huni Kuin. Nessa transição, a escola da vida e das experiências desse povo vai assumindo outros contornos. Nesse percurso discursivo, apresentam-se os desafios enfrentados por José Domingos Kaxinawa, na ocasião da transição do contexto étnico-territorial para outro contexto social. Nessa perspectiva, destacase o surgimento da cidade de Santa Rosa do Purus e, com ela, a escravização da mão de obra indígena, atrelada à chegada dos nordestinos ao Acre, por volta do segundo ciclo da borracha. A língua portuguesa suplanta a língua dos povos e se constitui passaporte para a inserção social dos povos indígenas em outros grupos, mas que apesar disso, são (in)visibilizados nesse contexto e, principalmente, na escola não indígena.

Nessa narrativa, mantivemos diálogo estreito com Bauman (2005), Santos (2010), Goody (2012), Veiga-Neto (2003) e Candau (2012), dentre outros autores que tematizam questões indígenas, da supremacia da Língua Portuguesa e territoriais da região. Argumentamos, que para o indígena se manter na escola, da forma como ela historicamente vem se apresentado, precisa silenciar a própria cultura. Argumentamos ainda, dialogando com Santos (2010), que os conhecimentos que dão vida à escola, a qual o narrador vivenciou, são 
abissais. Esses conhecimentos, que orientam as práticas escolares, distinguem os participantes da escola em dois lados/reinos, separados por linhas imaginárias, porém radicais. Do lado direito, estão os plenamente visíveis, dando sustentação ao trabalho realizado na e pela escola. Do lado esquerdo, encontram-se os invisíveis, os quais são considerados inexistentes. Nas palavras de Santos (2010, p. 24), ao analisar a sociedade contemporânea, as "linhas radicais [...] dividem a realidade social em dois reinos, o reino de "este lado da linha" e o reino do "outro lado da linha". A divisão é tal que o "outro lado da linha" desaparece à medida que a realidade se torna inexistente [...]".

Assim, em meio às condições impostas pelo universo colonizador, apresentamos José Domingos e sua trajetória escolar com oportunidades que o conduzem a outros espaços sociais. O acesso à escola do Estado, oportunidade de cruzar outros caminhos, os programas do governo e a transformação política da cidade da qual ele passará a fazer parte diretamente, como viceprefeito, são elementos marcantes dessa trajetória discursiva que teve início na "escola do barracão".

\section{ESCOLA DO BARRACÃO: LÍNGUA E PODER}

No seringal não tinha escola. O dono de seringal convidou um professor não indígena para dar aulas pra os filhos dos trabalhadores indígenas e não indígenas. Era pra ensinar a língua portuguesa e as contas... Na escola, nós éramos proibidos de falar na gíria, em nossa língua, quando falávamos as outras crianças mangavam. José Domingos Kaxinawá

O avô e o pai de José Domingos residiam na colocação situada no Seringal Vista Alegre. Seu patrão era um homem branco, vindo do nordeste brasileiro por ocasião do segundo ciclo da borracha, para investir na extração e comercialização da seringa. Nesse período, ressalta o narrador, sua família se espalhara por todo o seringal, situando-se cada uma em uma colocação de seringa, local onde teve os primeiros ensinamentos da leitura e escrita na Língua Portuguesa. Era o tempo do cativeiro, época em que os seringalistas inseriram a população indígena na extração do látex, estabelecendo uma relação de trabalho extremamente injusta, em que o indígena sempre ficava devendo ao patrão no processo de permuta entre bens de consumo e as bolas de borracha. Ele conta que para alfabetizar as crianças dessa comunidade na Língua 
Portuguesa e nas noções de aritmética, o patrão seringalista convidara um professor vindo do município de Feijó-AC para ministrar os primeiros ensinamentos.

Os estudos se davam no barracão e faziam parte os filhos dos indígenas que trabalhavam na extração da seringa, juntamente com outras crianças não indígenas, filhas do dono do seringal e de outros trabalhadores. No processo de ensino, utilizavam a carta de ABC, com a prática da soletração, da cópia e de leitura de palavras soltas, descontextualizadas. A língua pano era rigorosamente proibida e, em ocasiões em que um indígena a pronunciava, era motivo de zombaria, ou nos termos do narrador, de 'mangar'. Isso fazia com que José Domingos se sentisse envergonhado e evitasse ao máximo falar a língua de seu povo.

Se refletirmos sobre as condições de ensinamentos da leitura e escrita trazidas no relato de José Domingos, é impactante perceber a condição hierarquizante a que eram submetidas as Línguas Portuguesa e indígena, nesse contexto. Enquanto língua das minorias, embora representativa da maioria da população que habitava aquele espaço, as línguas dos indígenas foram relegadas à condição de inferioridade e de mangofa. A escola do barracão era dirigida por um "professor" vindo da cidade de Feijó-AC, certamente era uma pessoa que galgara a série mais elevada da hierarquia serial da escola estatal, disponível na localidade, e que se dispunha a viver no seringal para reproduzir com os indígenas, de forma perversa, suas experiências de estudante vividas na escola da cidade. Nessa toada, as línguas indígenas eram ridicularizadas e ignoradas, como estratégia para dificultar a propagação da cultura desse povo. Nesse aspecto, a escola do barracão foi extremamente eficiente para negar de forma sistemática as línguas indígenas, uma das características marcantes da identidade étnica, inviabilizando, por meio da proibição e do constrangimento, a continuidade de falá-las. Todo o trabalho da escola do barracão caminhou para apagar as línguas e, ao mesmo tempo, dificultar situações promotoras de interculturalidade, no contexto educativo.

Conforme Freire (2004), o uso da língua como instrumento de poder teve início desde os primórdios de nossa história. O autor revela, ainda, que no século XVI existiam, na Amazônia, mais de 700 línguas indígenas e não se falava ainda a Língua Portuguesa. Com a chegada dos missionários e soldados ao Grão-Pará, por volta do século XVII, foi que, de forma impositiva, disseminaram a Língua Portuguesa. Em consequência dessa imposição, na segunda metade do século XIX, o monolinguismo passou a imperar como língua entre os falantes indígenas e não indígenas daquele século. 
Por decorrência da resistência dos falantes, algumas línguas indígenas ainda são preservadas até hoje. Isso fez com que muitos indígenas passassem a ser considerados bilíngues. A Língua Portuguesa e a Língua Geral deixaram marcas históricas, por serem utilizadas como meio de comunicação entre povos de diferentes etnias. A Língua Geral, também denominada de nheengatu, aos poucos cede poder hegemônico à Língua Portuguesa. Desse modo, no século XIX, essa língua decretou seu império sobre os povos da Amazônia, permanecendo a LG apenas entre os povos do Rio Negro (FREIRE, 2004).

Em estudos sobre contextos bilíngues de minorias, Cavalcanti (1999) cita três motivos pelos quais esse tema tem resultado em muitos estudos na área da Linguística. O primeiro se refere ao fato de que o monolinguismo aparece, no Brasil, em forma de mito e, por assim ser, a intenção fora apagar as línguas das minorias, dentre elas, as línguas das nações indígenas. $\mathrm{O}$ segundo motivo, sugere a autora, ocorre pela associação do bilinguismo à língua de prestígio, gerando a invisibilidade dos contextos bilíngues, em que as línguas faladas de tradição oral fossem estigmatizadas. Ainda existe, atualmente, no Brasil, diversidade linguística, porém, o número de falantes é bastante reduzido. Cavalcanti (1999), mesmo sem tanta precisão, deduz ser em torno de $0,2 \%$, em universo de 250.000 pessoas da população brasileira, falantes das línguas sobreviventes.

No que tange às lutas pela preservação das línguas indígenas, sabemos que já no início dos anos 1980, em função da meta do governo em promover integração das populações nacionais, produziu-se número significativo de projetos na área da educação indígena no País, financiados pelas agências humanitárias internacionais. A intenção em relação às populações indígenas era unicamente a integração destas à comunidade nacional, através dos conteúdos ministrados com ênfase na Língua Portuguesa e, consequentemente, ignorando os aspectos relativos à cultura dos povos indígenas, em especial, à língua materna (WEBER, 2006).

Por outro lado, as lutas indígenas por reconhecimento dos anos 1970-1980 lograram êxito, com a inserção de suas reivindicações na Constituição Brasileira, aprovada em 1988. No artigo 210, parágrafo segundo, é dado outro direcionamento para o processo de integração. A partir desse dispositivo, criou-se a possibilidade de nova política educacional, garantindo o uso das línguas indígenas no processo de escolarização. Essa perspectiva ganha robustez com a aprovação da Lei de Diretrizes e Bases da Educação Nacional - LDBEN, número 9.394/1996. Os artigos 78 e 79 das disposições gerais da LDBEN e as Diretrizes Curriculares da Educação 
Escolar Indígena (1998) garantiram uma educação diferenciada, bilíngue, multilígue, intercultural e comunitária (FERNANDES; CAMARGO, 2020).

A inclusão das causas indígenas, nesses aparatos legais nacionais, foi resultante das lutas históricas dos povos indígenas, fazendo com que, no caso da educação, o Ministério da Educação (MEC) alterasse sua estrutura organizacional, criando de forma inédita a Coordenação Nacional de Educação Indígena, vinculada ao Sistema de Ensino da União (SEF). Os Referenciais Curriculares Nacionais para as Escolas Indígenas (RCNEI) consistem em outra conquista que ocorreu na sequência desse processo que teve como foco a educação bilíngue e intercultural (WEBER, 2006).

Por outro lado, a inclusão de dispositivos nos ordenadores legais não se constitui garantia de uma educação intercultural e bilíngue nas práticas escolares. Não é algo simples de executar, requer vontade política nas macro e micro relações, como bem enfatiza Walsh (2013). Além disso, carece, antes de tudo, conhecimento amplo da diversidade cultural que matizam o chão da escola, que as permitam diferentes situações de troca, de misturas culturais, sem a desvalorização de uns sobre outros e que evidenciem suas origens. Candau (2012) ressalta as diferentes tensões existentes entre o discurso e as práticas interculturais e a importância de apresentar possibilidades de realização de práticas interculturais no contexto escolar.

É importante destacar a trajetória da interculturalidade na América Latina para o conhecimento da temática. Mas, tão relevante quanto essa caminhada, é verificar como essa perspectiva intercultural vem se apresentando, ao longo desse processo, na educação dos povos indígenas. Nesse aspecto e subsidiada pela fala de Catherine Walsh, no XII Congresso da Association pour la Recherche Interculturalle, ocorrido em 2009, no Brasil, Candau (2012) expõe três concepções de educação intercultural, das quais trazemos duas, a funcional e a crítica, por se articular à narrativa de José Domingos. A primeira, diz respeito à interculturalidade funcional, de caráter acrítico. Essa perspectiva não questiona as relações de poder que se dão entre os diferentes grupos sociais, apenas cedem em relação ao discurso oficial e legal. Ajustam as lutas por direitos dos povos indígenas, historicamente negados, à legislação, mas sem qualquer alteração das relações que se estabelecem com esses grupos minoritários. Os diferentes continuam sendo tratados de forma padronizada, como se iguais fossem, perpetuando, de forma mais sutil, a ausência histórica dos direitos de ser, de interconectar culturas e de efetivas oportunidades, os colocando na condição de assimiladores da cultura hegemônica. 
Por outro lado, a interculturalidade crítica, ao contrário da primeira, questiona a assimetria social, pelo fato de não possibilitar diálogo social favorável à construção de novas relações profícuas à democracia e às condições igualitárias entre os diferentes grupos sociais (CANDAU, 2012). A partir da reflexão sobre as práticas, em prol da interculturalidade e das performances que estas assumem no contexto social, Candau (2012) apresenta propostas de introdução da interculturalidade crítica no contexto escolar. Indica como ponto de partida uma intervenção curricular que contemple um projeto que possibilite diálogo permanente entre os saberes dos diferentes grupos sociais, em uma perspectiva em que "a interculturalidade se situe em um horizonte político de construções de Estados não somente pluriculturais e multilíngues, mas, também, para alguns, a possibilidade de avançar na construção de Estados plurilíngues" (CANDAU, apud WALSH, 2013, p.155). Neste sentido, apresenta projeto bastante desafiador para o contexto educacional brasileiro e faz com que se compreenda o quão devagar ainda caminha a educação para o alcance desses propósitos.

Hoje, é possível mapear a existência de diferentes contextos bilíngues no Brasil. Porém, o contexto acreano não diferente do que sucedeu em outras partes do país, a vitalidade das línguas indígenas vem continuamente perdendo forças. A prática bilíngue, que se dava entre os povos indígenas do Acre, aos poucos, vai sendo fragilizada pelas condições impostas que induzem à desvalorização da língua original desses povos, como destaca Weber (2006), ao descrever sobre as festas dos povos Huni Kuin, realizadas nos seringais, localizados próximos aos Rios Muru e Humaitá, por volta do ano 1994. De acordo com a etnografia feita por essa autora sobre os Huni Kuin, "falava-se pouco português, o suficiente para que fosse possível uma comunicação básica entre eles e os Cariús (pessoa não indígena). A língua Hãtxa kuĩ era chamada de gíria, o que bem revela o baixo prestígio perante a língua dominante, o português" (WEBER, 2006, p. 66). No entanto, a autora esclarece que a língua dos kaxinawa era falada no recinto doméstico, garantindo, até então, a transmissão entre os membros da família, mas que aos poucos foi perdendo a vitalidade. Verifica que "grande maioria dos jovens que nasceram a partir dos anos 80 não usa mais (entende mais não fala) a língua Hãtxa kuĩ, enquanto a geração imediatamente anterior (70) é bilíngue, dominando com fluência a língua materna e o português" (WEBER, 2006, p. 95).

Na mesma perspectiva da autora anterior, Baniwa (2016), ao abordar questões referentes à interculturalidade das línguas indígenas, critica a hierarquização linguística, esclarecendo que 
a distinção entre as línguas não as coloca em condições de superioridade ou inferioridade na relação entre si. Afirma que "o mundo é o resultado de um protocolo de comunicação entre todos os seres, criadores e criaturas" (BANIWA, 2016, p. 42-43). Como pertencente aos povos indígenas, Gersem Baniwa explica como ocorre o sistema de comunicação cósmica entre esses povos. Ressalta que existe sistema complexo de comunicação entre os seres humanos, estejam eles vivos ou mortos, e entre estes e a natureza, o que se faz acreditar que essa visão de mundo também está presente em outras comunidades indígenas.

Em se tratando dos povos Huni Kuin, essa possibilidade é constatada quando buscamos explicações na mitologia sobre o mundo, trazida por esse povo. Souza (2017), em sua dissertação de mestrado, dialogando com o filósofo italiano Emanuele Coccia e o antropólogo Lévi-Strauss, reitera a acusação à perspectiva científica eurocêntrica sobre as realidades, que não permite ou dificulta todo tipo de conhecimento que nasce dos sentidos. Enfatiza a pouca importância dada pela filosofia no tocante às influências do sensível na construção do pensamento humano, resultando na separação entre o racional, próprio do humano, do sensível que abriga os outros animais. Esse último aspecto, articulado à racionalidade, envolve a visão mitológica do povo Huni Kuin e, essa dimensão, necessariamente, precisa ser compreendida, principalmente no âmbito da escolarização desse povo. Se Baniwa (2016) fala do protocolo de comunicação cósmica entre todos os seres (vivos ou mortos) e a natureza, Souza (2017) vai evidenciar esse aspecto sensível entre todos os seres e a natureza na literatura Huni Kuín, caracterizando a ineficácia da separação da racionalidade, representada pela ciência, e do mítico e místico da dimensão sensível, a qual essas comunidades se orientam.

Nessa mesma perspectiva, assentado em bases que explicam como se desenvolve o pensamento de um povo, ao longo da história da humanidade, Goody (2012), no livro intitulado A domesticação da mente selvagem, permite aos leitores a perceptibilidade em relação à constituição do pensamento binário, o qual se estabelece dividido em dois polos: de um lado, a racionalidade (representada pela ciência, visão eurocêntrica de mundo); e do outro, a irracionalidade (pensamento empírico, de bases mitológicas), estando o pensamento racional sobreposto hierarquicamente ao pensamento lógico-empírico. Reconhecendo que o pensamento de ordem pragmática e de ordem intelectual se completam, esse autor coloca como problema o fato de um sobrepor-se ao outro. Essa superposição é a maneira encontrada a partir da qual são colocadas as diferenças em nossa sociedade. As diferenças pautadas nas categorias nós/eles que se encontram enraizadas em nossa maneira de pensar etnocêntrica, a qual caracteriza a 
influência da expansão europeia na forma de ver o outro, pode ser uma vertente explicativa para a exclusão. O outro está dentro da margem do "eles”, aqueles que estão em uma condição de inferioridade ao "nós". O "ele" é visto como o irracional, o de mente selvagem que precisa ser domesticado. No entanto, essa visão equivocada do outro não considera as mudanças ocorridas, ao longo da nossa história, na forma de pensar. Como explica Goody (2012), há uma íntima relação entre os processos de dominação mental e os processos de dominação social por apresentarem, esses últimos, as circunstâncias materiais favoráveis à dominação do pensamento, como também as formas de vidas futuras.

Trazendo para o contexto linguístico, em que a língua indígena é negligenciada em relação ao português, ainda com a mesma obra de Goody, verificamos que as transformações da fala nas formas gráficas, culminou no desenvolvimento da escrita e, a partir de então, na adesão ao comportamento de ler e escrever. É justamente a partir desse ponto que o autor ressalta o valor da fala na construção da escrita e, consequentemente, a impotência da cultura oral na construção de conhecimentos sobre a realidade. Assim, tece críticas sobre como vem sendo tratado o processo de ler e escrever nas salas de aula, ou seja, entrelaça crítica rigorosa à prática da sala de aula que se desdobra em um abstracionismo como base para construção do conhecimento. Esse aspecto é plenamente observável na narrativa de José Domingos, os valores trazidos da oralidade da sua língua Hãtxa kuĩ foram ignorados.

Ainda enfatizando a questão do pensamento binário, em investigações sobre as sociedades pré-letradas, Goody (2012) aborda a influência negativa dos meios de comunicação no pensamento intelectual dessas sociedades. Procura mostrar as riquezas que trazem o pensamento pré-letrado, seja através dos mitos, da religião, ou do pensamento matemático, e da forma de organização administrativa. Todas essas formas de pensamento evidenciam a existência de atividade intelectual. No entanto, a visão binária oferece destaque a um "ele" que consiste no "outro", aquele cuja condição de diferença é sempre inferior ao "nós". Esse "nós", por se tratar de um coletivo que reproduz a cultura eurocêntrica, imperativa e silenciadora das demais culturas e dentro delas as línguas indígenas, vem apagando todas as manifestações diferentes ao longo dos anos. A educação e, mais especificamente a escolar, tem se destacado como veículo responsável por esse apagamento cultural, que silencia os sujeitos indígenas, como bem retrata a narrativa de José Domingos sobre a escola do barracão, que os proibiam de falar a sua língua e quando isso acontecia, por resistência de seus corpos, eram ridicularizados, 
servindo de mangofa e zombaria, inclusive pelos colegas não indígenas da turma. Esse modus operandi da escola, reiteradamente tem desconsiderado as características individuais e as particularidades das diferenças, disseminando sistematicamente a visão eurocêntrica de ver o mundo, trabalhando, dessa forma, para o fortalecimento do poder dos grupos sociais, culturalmente mais próximos da visão europeia.

\section{CHEGADA DA IGREJA E INGRESSO NA ESCOLA PÚBLICA}

Se compararmos os tempos de hoje com os de antigamente, nós, adultos e crianças, não aprendemos como antes. Antes, tínhamos os pajés que nos ensinavam muito sobre os conhecimentos de nossos ancestrais: os nossos costumes e crenças. Esses conhecimentos não são valorizados pelos que vivem na cidade.

José Domingos Kaxinawa

Nos anos 1980, Padre Paulino Baldassari foi às terras do Purus, com a missão de batizar as crianças indígenas, explica José Domingos, período em que se deu a demarcação de terras no Purus. De 1985, quando ocorreu a demarcação, até hoje, têm-se 260.000 hectares de terras demarcadas, nas quais habitam em torno de 10.000 Huni Kuin.

A irmã mais velha de José Domingos, antes prestando serviço no posto de saúde instalado na aldeia, foi preparada pelo missionário para exercer a função de professora na aldeia. Em uma casinha de palha, passou a dar aula para os irmãos e outros filhos da comunidade. Segundo o narrador, seus ensinamentos sobre a Língua Portuguesa foram fundamentais para que prosseguisse seus estudos, Ensino Fundamental e Médio, na atual cidade de Santa Rosa do Purus. Embora fosse indígena, o que caracteriza uma conquista grande para a aprendizagem da comunidade da aldeia, pois o universo cultural da professora se fundia ao da comunidade aprendente, predominaram no seu trabalho pedagógico os aparatos didáticos do ensino da Língua Portuguesa e do ensino do catecismo da igreja católica. Por outro lado, deu condições a José Domingos continuar os estudos na cidade, quando as circunstâncias permitiram.

Nos anos 1980, quando Santa Rosa do Purus já se constituía em uma Vila do município de Manoel Urbano-AC, José Domingos evidencia a mobilização do Padre Paulino Baldassari que muito fez pela organização de um grupo de lideranças, envolvendo indígenas e não indígenas, com a representação dos povos Huni Kuin e Colinas que por lá residiam, para irem 
a Rio Branco-AC requerer ao governador a transformação de Santa Rosa do Purus em município do Acre.

Como resultado da organização social, liderada pelo Padre Paulino Baldassari, realizouse plebiscito, a partir do qual a vila de Santa Rosa do Purus foi eleita município, pela Lei Estadual n. 1.028, de 28 de abril de 1992. Com isso, ocorreu o desmembramento das terras desse novo município do já município de Manuel Urbano. José Domingos explica que o fato do município de Santa Rosa do Purus fazer limite com o Peru facilitou a vinda de muitas famílias cariús peruanas e de outros representantes do povo Huni Kuin, assim como de outros municípios que fazem fronteira com esse rio, como Feijó, Manoel Urbano e Tarauacá, sendo sua população basicamente constituída por pessoas de origem desses territórios circunvizinhos. Com a transformação da Vila em município, aos poucos, as benfeitorias foram sendo conquistadas. Por esse tempo, a família de José Domingos construiu residência na cidade de Santa Rosa do Purus, onde ele deu continuidade aos estudos. A escola, não mais de palha, nem tendo a irmã como professora, ganhou outros formatos. Passou a ser regida pelas leis estaduais, leis do branco. Nessa nova realidade, a condição de invisibilidade do indígena volta a ser a regra, é retomada de forma mais estruturada a condição da escola do barracão. O indígena se constituiu no "outro", no invisível, naquele que fica no lado esquerdo da linha imaginária (SANTOS, 2010), do diferente de nós, que para se manter na escola e integrar-se a nós, necessitava silenciar, apagar o seu ser até ali construído no seio do seu povo, embora a população escolar do município fosse, à época, majoritariamente indígena e o território em que a escola estava alocada fosse povoado por Huni Kuin e Colinas.

\title{
4 ESTAR NA ESCOLA DA CIDADE: A CONDIÇÃO DE UM SUJEITO “OUTRO"
}

\begin{abstract}
Na escola do branco compramos farda e comemos merenda industrializada. Tem tudo com horário certo, com ritmo lento e vários professores. As crianças bagunçam e tratam o índio com preconceito. Nossos pais diziam que era preciso ter paciência. Aguentar calado porque precisávamos aprender. Quando uma criança indígena bate em criança branca os pais são chamados, tem até conselho tutelar e reunião. As crianças indígenas aprenderam a bagunçar com elas. José Domingos Kaxinawá
\end{abstract}

A busca pelo saber na escola da cidade tinha como principal desafio a competência na leitura e escrita do português. Para José Domingos, estava evidente que essa seria uma condição 
indispensável para a ascensão social, porém, não diferente de outros momentos de seu caminhar, essa parte de sua trajetória lhe trouxe muitos desafios, quase que intransponíveis.

$\mathrm{Na}$ escola da aldeia, as experiências emergiam a partir da necessidade de compreender as condições favoráveis para caça, pesca, plantio do milho, arroz, macaxeira, por exemplo, sobre o comportamento entre eles e a explicação para muitos fenômenos que surgiam na natureza e em meio social. Por meio de histórias orais partilhadas pelos mestres, envolvendo curas, dentre outras sabedorias, como é o caso daquelas voltadas aos estudos da natureza e sociedade, o trabalho pedagógico ia sendo construído no ritmo do próprio caminhar, integrado à comunidade a qual a escola estava inserida.

$\mathrm{Na}$ escola da cidade, aquela integração que havia na escola da aldeia deixou de existir. As balizas que orientavam essa nova escola de José Domingos passaram a ser outras. As folhas do livro didático eram seguidas linearmente, independentemente dos alunos que constituíam as séries hierárquicas da escola. Tudo era definido previamente e tinha como base fundamental de orientação o livro de cada área de conhecimento para cada série, organizados a partir das regiões economicamente mais abastadas do Brasil. O quadro de giz era utilizado para grafar grandes cópias, como exercícios de treinamento da escrita. Muitos não acompanhavam a leitura, menos ainda compreendiam o contexto e os textos, os quais escreviam, constituindo em exercícios mecânicos, fora de qualquer articulação com o mundo desse "outro" que ali estava presente. Essa maneira fragmentada, das folhas do livro ou expostos em um quadro de giz, para que fossem copiados e memorizados como condição de promoção a uma série seguinte, era a regra.

Esse tipo de dicotomia que se faz perceber na prática curricular vivenciada na escola frequentada pelo narrador, Goody (2012, p. 156-172) denominou de "A grandiosa dicotomia considerada". Segundo esse autor, merece atenção o conjunto de fatores sociais que devem ser examinados, os quais contribuem para a diferenciação das sociedades letradas e não letradas. Destacando essa dicotomia, dentre outras que são consideradas como base de diferenciação entre as sociedades, procura trazer novo olhar sobre as diferenças, tendo a escrita como principal objeto para análise. Para ele, é importante compreendermos as consecutivas mudanças de uma sociedade pautada no oral para uma que tem a escrita como fator primordial na comunicação entre os sujeitos.

Embasado em Sartre, que afirmava não haver história sem arquivo, Goody (2012) faz uma leitura crítica sobre as diferenças, por julgar ser a descontinuidade apresentada por alguns autores como forma de explicação para as diferenças uma forma de estabelecer a dicotomia 
sobre tais diferenças. Neste sentido, de maneira fragmentada, apresentam a polaridade presente na dicotomia mito-ciência, concreto-abstrato. Assim como acontece na escola, em que os textos são selecionados por um público letrado para o não letrado, desprezando por inteiro o conhecimento potencial que traz esse público, para tratar de determinados assuntos ali abordados.

Goody (2012) ressalta a importância do olhar sobre as condições de reprodução do conhecimento. Explica que a emergência da história está conectada à escrita, o que induz a observação da influência das condições de produção do conhecimento na maneira de pensar da humanidade, em diferentes tempos e espaços. Esse fato faz concluir que as diferentes maneiras de ver e entender a realidade não estão ligados diretamente à genética, ou a etnia de um povo e, sim, às condições sociais que lhes são dispostas. Goody (2012, p. 171) explica ainda que "o problema do pensamento humano não pode ser tratado apenas na perspectiva do universal. Há uma diferença entre estilos cognitivos e as diferenças culturais”. O indígena é considerado aquele de poder cognitivo inferior, por ser comum ter os conhecimentos socializados a partir da expressão oral e a escola é o espaço onde fica mais evidente essa dicotomia entre "ele", sujeito indígena e "nós", os oriundos de uma sociedade letrada, a qual se diz ter conhecimentos válidos a ser ensinados para aqueles que não têm nada de grande valor a dizer. A negação da língua desse "outro" é o meio mais eficaz para essa imposição cultural. Imposição de uma cultura de origem eurocêntrica e hegemônica. Embasada nesses argumentos e como resultado da forma de pensar moderna, a escola se constituiu e interiorizou-se pela floresta brasileira, tentando homogeneizar saberes e formas de pensar, desconsiderando as diferenças entre outros grupos que constituem o território nacional.

Diferente de outros parentes, José Domingos "domesticou-se" dentro dos pressupostos orientadores da escola moderna, conseguira dar prosseguimento aos estudos e passou a trabalhar no posto de saúde pela Fundação Nacional do Índio (FUNAI). Mas, ao chegar o período de cursar o Ensino Médio, transferiu-se para a cidade de Rio Branco-AC para frequentar a Escola Lourival Sombra. Foi o primeiro passo para outras "conquistas" advindas dessa oportunidade. 


\section{ESCOLA DA CIDADE DE RIO BRANCO: CRUZAR FRONTEIRAS E RETORNAR ÀS RAÍZES}

O índio vem pra cidade pra aprender a Língua Portuguesa. Na comunidade, os parentes não sabem. Precisamos aprender pra saber ensinar os índios da nossa comunidade. José Domingos Kaxinawá

A ida de José Domingos para Rio Branco-AC se deu pela necessidade de cursar o Ensino Médio. Quando indagado sobre como se sentia em uma cidade bem maior, disse sentir-se bem, pois, ninguém mexia com ele. Gostava de ficar em um canto da sala, fazendo suas atividades escolares e ouvindo o professor. Porém, mesmo que, às vezes, não entendesse bem a língua, procurava ficar atento para aprender.

Ao falar que "ficava quieto em um canto da sala sem mexer com ninguém, ter paciência porque precisamos aprender”, evidenciamos no discurso do narrador, que desde cedo aprendeu a visão de integração e assimilacionista, imposta simbolicamente pela escola, uma vez que exige comportamentos baseados nas posturas e nos discursos predominantes que permeiam o espaço escolar. Não se misturar, ficar em um canto e a necessidade de ter paciência, passando por cima da condição humana para ter algo que lhe é de direito, são reveladoras de sinais da intolerância da escola com o diferente. Qualquer diferença é imediatamente trabalhada pedagogicamente, no sentido de moldá-la e integrá-la ao considerado "normal", a partir dos parâmetros de sujeito e de sociedade, idealizados pelos padrões eurocêntricos historicamente construídos.

Veiga-Neto (2003), ao refletir sobre o papel do discurso na constituição do sujeito, relembra que nascemos em um mundo de linguagem, linguagens que compõem discursos que circulam nesse mundo, a partir dos quais nos definimos entre os jogos de poder que permeiam os macros e micros espaços. Somos definidos, portanto, a partir de jogos de poder. Ao citar Foucault, esse autor argumenta sobre o poder da palavra em um contexto discursivo, no qual ganha significados sobre nós, o outro, e sobre o mundo. Nesse contexto interpretativo, se pensarmos no universo de sentidos que compõem o contexto do indígena e do não índio, a escola trata de cumprir o seu papel, a partir do quadro de referência idealizado e normatizado como o mais correto. Os profissionais que implementam pedagogicamente esse desiderato são também preparados academicamente sob os mesmos ideais de correção, estabelecendo uma correlação de força desigual entre os diferentes, cabendo aos mesmos um silenciamento que 
revela muito sobre esse processo, muito bem expressado por José Domingos, quando diz que ficava pacientemente quieto no canto da sala, sem mexer com os demais.

Como parte integrante do jogo de poder que impera no todo social, a escola está a serviço do Estado com seus fazeres pedagógicos. Entre os muitos silêncios que permeiam as diferentes linguagens que tecem múltiplos sentidos, a escola idealizada como a benfeitora de todos os processos, vai disseminando entre os diferentes discursos favoráveis à integração e à assimilação dos diferentes a um mesmo que o Estado requer. Põe em prática as ações primordiais para indução da propagação de um modo de ser, contribuindo com a continuidade do poder, localizado em determinados grupos e, deste modo, porta-se, de maneira indiferente, às condições culturais dos sujeitos indígenas que ali estão.

A escola da cidade fez parte de uma parcela significativa da construção identitária de José Domingos. Ser aluno em uma escola do não indígena na capital fazia parte da sua constituição identitária, era seu desejo, crença que seria a âncora para muitas conquistas sociais. A escola é tracejada por cenários de guerrilha de identidades, organizadas e categorizadas, conforme o grupo oriundo de cada sujeito. Aquele cuja identidade está associada a outros grupos, é negado. E o é, por estar culturalmente distante do modelo cultivado pela escola, ou mesmo, "excluído do espaço social em que as identidades são buscadas, escolhidas, construídas, avaliadas, confirmadas ou refutadas" (BAUMAN, 2005, p. 46). No contexto em que estamos enfocando e assemelhando-se ao que Bauman (2005) analisa sobre as identidades impostas, o "outro" é representado pela figura do indígena (José Domingos) que traz identidade imposta a partir das diversas facetas utilizadas pelo discurso escolar. Deslocados da condição de sujeitos potentes, criador de cultura de riquezas imensuráveis, são relegados à condição de inferioridade em relação ao não indígena, que para continuar a sobreviver no espaço escolar, representa outra identidade que apaga valores, modos de ser, construídos no âmbito do seu grupo de origem.

Na condição de aluno da escola oficial da cidade de Rio Branco, José Domingos, mais uma vez, depara-se com um universo que historicamente traz o peso de comportamentos preestabelecidos. Ficar quieto, para assim ter acesso a direitos que poderiam fazer dele um "verdadeiro cidadão", foi a chave que encontrou para se manter naquele território, mas que lhe impunha um alto preço. Deslocado, enfrentando as restrições e os embargos do espaço escolar, sem que fosse permitido transparecer os aspectos culturais que lhe constituía, foi ficando em 
silêncio, recolhendo-se a um canto, no espaço do fundo da sala, mantendo-se paciente diante das demonstrações de superioridade, de preconceitos e com a marginalização a qual lhe destinavam. Ocupou o espaço do canto do final da sala de aula, no cantinho reservado ao silêncio dos silenciados.

Bauman (2005) afirma ser a identidade um dos fatores de maior influência na estratificação social. Segundo esse teórico, existe bipolarização hierárquica na sociedade global que se apresenta, tendo-se de um lado do polo a possibilidade de escolha própria do sujeito, a partir de um leque de oferta disposto universalmente. No outro polo, têm-se aqueles cujo direito de escolha lhes foram negados, os submetendo à imposição da identidade imposta de fora, por parte de outros. Considerando ainda o que Bauman (2005) analisa sobre a formação das identidades na modernidade líquida, que enfatiza que elas se constituem a partir das condicionantes que envolvem os sujeitos, ora com a possibilidade flutuante de escolha, ora pelo discurso pré-determinado, podemos afirmar que a identidade demonstrada pela narrativa de José Domingos não foi certamente a de livre escolha. É possível reconhecer o poder dos discursos pedagógicos na constituição desse outro (José Domingos), quando "decide" negar provisoriamente a identidade construída no âmbito do seu povo, estabelecendo um comportamento de submissão, não impondo enfrentamento e resistência, bem perceptível na sua narrativa.

Em meio aos silêncios marcantes impostos pela escola, percebemos na sua narrativa que no dia do índio reascendia nele a possibilidade de vivenciar sentimentos de pertencimento, dando visibilidade "respeitável" à sua identidade étnica. Nessa única data dos duzentos dias letivos anual, previamente era programado um evento de homenagem consentida, no qual lhe era oportunizado falar de si e do seu povo. Em uma abordagem folclorista (ORTIGÃO, 2018), José Domingos narra que "no dia do índio era convidado a falar sobre sua cultura, dava palestras, era ouvido por toda escola", uma maneira bem apropriada para reforçar a visão estereotipada do indígena na sociedade. Um momento espetacular, criado para a escola ter oportunidade de dizer, embora indiretamente, a quem é autorizado o direito e quem é esse "outro", como ele se constitui, dito pelas suas próprias palavras, demonstrando a sua identidade, em uma condição de confissão oral que fortalece o discurso do poder dominante, através de uma narrativa que atua de maneira colaborativa com o discurso do poder alimentado pela ideia trazida pelas identidades nacionais (POSSENTI, 2009). 
Nos anos 1990, tendo concluído o $2^{\circ}$ grau (Ensino Médio), José Domingos se submeteu a um concurso para professor efetivo em Rio Branco-AC, a partir do qual se tornou professor efetivo da rede pública, dando-lhe condições de retornar à cidade de Santa Rosa do Purus, instrumentalizado pela tecnologia ocidental, eurocêntrica, colonial e hegemônica da perspectiva integracionista, para o trabalho docente na aldeia.

\section{DO TRABALHO DOCENTE AO INGRESSO NA UNIVERSIDADE}

Nas aldeias são oferecidos vários programas: Asinhas para alfabetizar crianças e adultos, e tem também a educação infantil de 3 a 5 anos. Depois, aguardando o nível superior, a universidade.

José Domingos Kaxinawá

Desde 1995, José Domingos como efetivo professor, ministra disciplinas das áreas que compõem o currículo da Educação Básica na escola da aldeia e nessa condição, atendia os critérios estabelecidos para ingressar em um programa de formação docente no Ensino Superior. No ano de 2015, a Universidade Federal do Acre (UFAC), por meio do Plano Nacional de Formação de Professores da Educação Básica (PARFOR), possibilitou o ingresso dos professores do município de Santa Rosa do Purus no Curso de Pedagogia. Essa política de formação de professores, gestada pelo Ministério da Educação (MEC), é direcionada a professores sem formação superior, mas que por carências regionais do território nacional, ingressaram no magistério da Educação Básica. Neste sentido, a todos os professores que naquele ano se encontravam em pleno exercício profissional e vinculados às redes de Educação Básica de Santa Rosa do Purus, sem a formação exigida legalmente, fora permitido o ingresso nessa política de formação.

Naquele ano, fora inaugurado o Ensino Superior no município de Santa Rosa do Purus com uma turma, a qual José Domingos fez parte. Em sua narrativa, é afirmado o quanto os anos de duração do Curso de Pedagogia foram tempos difíceis. As principais dificuldades foram relacionadas ao conteúdo e às formas de implementação do curso. Tratava-se exclusivamente de conteúdos trabalhados na Língua Portuguesa. O tempo para ler extensos e complexos textos teóricos era insuficiente. Nesse aspecto, é importante ressaltar peculiaridades da política de formação do PARFOR para entender as razões pelas quais foram tão difíceis os tempos de curso para esse narrador. A estrutura curricular do campus da UFAC foi estendida para atender a essas 
comunidades, de conformação cultural bem diferente, para os quais esse curso fora pensado. $\mathrm{O}$ aporte teórico e técnico das disciplinas, estudados no campus sede da UFAC, durante dois semestres letivos de quatro meses cada, foram transferidos para essa turma, sendo estudados em apenas três meses de cada ano, de forma condensada e no período de recesso escolar das escolas da Educação Básica, significando quatro ou cinco anos sem férias.

Após o encerramento dos semestres letivos das escolas em que trabalhava, iniciava-se a jornada de formação superior, correspondendo aos meses de julho, janeiro e fevereiro. A cada semana desses meses, de segunda-feira a sábado, era ministrada uma disciplina, majoritariamente de sessenta horas cada, nos turnos da manhã e tarde, entrando pela noite, ou seja, das $7 \mathrm{~h} 00 \mathrm{~min}$ às $12 \mathrm{~h} 00 \mathrm{~min}$ e das $13 \mathrm{~h} 30 \mathrm{~min}$ às $18 \mathrm{~h} 30 \mathrm{~min}$ horas, totalizando dez horas exaustivas de aulas para completar a carga horária exigida. Essas jornadas intensas eram ocupadas para leituras de textos, comentários, debates e trabalhos que resultavam nas avaliações do aproveitamento dos conteúdos desenvolvidos nas disciplinas, muitas vezes, tendo que ocupar o restante da noite para lograr êxito nas atividades avaliativas. Ao analisar os textos estudados, podemos insinuar que além de serem extensos, eram predominantes aqueles que centram suas epistemologias em uma razão indolente, arbórea e abissal (SANTOS, 2001; 2010; 2009), que não reconhecem no outro, no aluno, possibilidades de saberes que se interconectam, modificam-se, reorganizam-se, não somente reproduzindo o mesmo do texto.

Hoje, José Domingos, professor contratado e com formação em nível superior, continua lotado em uma escola da aldeia para ministrar disciplinas de todas as áreas. Segundo ele, a escola tem estrutura totalmente diferenciada, comparada ao início de sua existência. Embora de caráter bilíngue, vê-se o investimento na Língua Portuguesa como um dos principais propósitos. Desenvolve a Educação Básica completa, sendo que, para as crianças em idade de educação infantil, quatro e cinco anos, tem o programa “Asas da Florestania” que permite a esse público ter aulas com instrutor na própria residência, pelos varadouros da floresta. No entanto, independente de ser na escola ou em casa, é o Estado quem monitora, ordena, decide.

\section{PALAVRAS FINAIS}

A narrativa apresenta um hiato entre os dispositivos legais conquistados pelos indígenas e as práticas desenvolvidas na formação. Em que pese todo o aparato legal, que passa pela Constituição Federal aprovada em 1988, a Lei de diretrizes e Bases da Educação Nacional, no 
9.394/1996, e as leis mais recentes, sabemos que tornar o currículo vivo da Educação Básica e do Ensino Superior intercultural, em uma perspectiva crítica, ainda é algo a se realizar. A narrativa de José Domingos demonstra esse distanciamento, mesmo estando a legislação brasileira apontando para essa possibilidade já por três décadas. Em uma sociedade cuja fonte inspiradora de todo o arsenal cultural e curricular ainda tem como parâmetro único o conhecimento ocidental, colonial, eurocêntrico, norte-americano, capitalista, e heteropatriarcal (SUSSEKIND, 2019), dificultam as reconfigurações práticas das unidades escolares, embora as pressões dos diferentes grupos tenham alcançado êxito no aparato legal.

Pensar as ações que se efetivam no cotidiano escolar e nas universidades, a partir de um imaginário social, pautado em uma lógica homogeneizante que categoriza os excluídos e os colocam em patamares inferiorizados, perpetuam a posição de supremacia do colonizador, sejam eles professores, gestores, técnicos, formadores de políticas, abrigados nas instituições, em condições plenas de continuidade. A legislação que favorece os grupos minoritários é apenas um pequeno passo importante, mas, tão relevante quanto, é pautar o trabalho educativo cotidianamente nas narrativas daqueles que se encontram do outro lado da linha imaginária, dos sujeitos historicamente excluídos. Implica dar voz a esses sujeitos e trabalhar com eles e não para eles. Nesse processo, desconstruir narrativas hegemônicas, criadas por outros grupos, em circunstâncias favoráveis de decifrar e comportar-se de acordo com o que o pensamento hegemônico requer para governar, mostra-se como uma das possibilidades, sejam elas estabelecidas nas micro ou macro relações sociais.

Superar uma história de negação do outro, o indígena, cavando espaços, fraturando até triturar o bloco homogêneo condensado, faz com que surjam outras narrativas na voz dos sujeitos negados, excluídos, silenciados. Fazê-los sujeitos, empoderar suas narrativas, implica micro e macro ações nos espaços sociais e principalmente nos territórios institucionais de educação/formação, os quais "todos" adentram e passam uma parcela significativa de tempo e de constituição identitária. Isso requer, indistintamente, estudo, desprendimento e desconstrução de nossas certezas, de nossas balizas analíticas e muitas lutas a partir de si e com os outros, por onde formos adentrando.

Como evidenciamos no início do artigo, desafiamo-nos a entender e analisar os fatores determinantes para a visibilidade conquistada por José Domingos, no ambiente da Educação Superior. Da mesma forma, perquirimos na sua narrativa quais teriam sido as experiências de 
vida que potencializaram José Domingos, dando-lhe visibilidade no espaço educativo na contemporaneidade, apesar da carga preconceituosa e de exclusão que foi levado a conviver. Percebemos que desde o seu ingresso na escola da cidade, ele percebeu que a resistência, o confronto não era estrategicamente o melhor caminho. A correlação de força entre os discursos era demasiadamente desigual. Ele era o "outro", não fazia parte do "nós" e no "nós" não cabia "ele", constituído de toda a sua carga cultural, estava posicionado do lado esquerdo da linha imaginária que separa os dois lados e polos. Desde a escola do barracão, seguido pelas escolas da cidade, ele foi subjetivando a sua diferença, que se constituía em barreira para viver neste mundo da escola ocidentalizada, pautada pelo discurso uníssono e unívoco. O seu mundo era demasiadamente diferente. Os seus mitos, a sua língua, o seu jeito, enfim, as suas características identitárias guardavam uma configuração que não era aceita e na escola isso ecoava estrondosamente.

Duas possibilidades se mostraram explicitamente. Evadir-se, como acontecia com a esmagadora maioria indígena que chegava às escolas das cidades, ou manter-se firme para submeter-se aos constrangimentos cotidianos e, pouco a pouco, aceitar a “domesticação". Salta aos olhos, no decorrer da narrativa, o enfrentamento dessas duas possibilidades. Chegar no patamar que chegou, evidencia a sua "escolha" e firmeza de propósitos. Com o discurso da "tolerância", da paciência, que se explicita no comportamento de "ficar em um canto da sala", encolhido para dar lugar àqueles julgados melhores e de comportamentos coerentes com os padrões exigidos, fora o escudo para aprender a linguagem hegemônica, para talvez trabalhar de forma empoderada contra ela.

O que se assistiu de José Domingos no Ensino Superior, com sua lógica de raciocínio concatenada, explicitada nos seus argumentos encadeados com as lutas de seu povo na e pela floresta, "impondo" visibilidade nesse ambiente de formação docente, representa uma das suas identidades construídas no trânsito entre o lado direito e o lado esquerdo da linha imaginária, que transcendeu o que era, mas que, por outro lado, não se tornou o que quiseram que ele se transformasse, mesmo tendo sido o ambiente escolar milimetricamente esquadrinhado para tornar esse outro (José Domingos) o mesmo de "nós", ele se constituiu um entre, um não lugar, difícil de ser capturado em sua totalidade, uma vez que ela não é única. As múltiplas identidades que lhe constituem se conformam a partir do contexto ao qual ele vai se inserindo e pelos interesses surgidos no espaço e tempo descontínuo da vida. Para exemplificar, podemos dizer que se na Educação Básica a sua constituição e interesses identitários eram uns, no Ensino 
Superior, passaram a ser outros, todos proporcionados pelo período da vida em que estava vivenciando, entendendo ser a identidade mutável e descontínua.

Por fim, ao longo da construção do artigo, procuramos argumentar, entremeando a narrativa de José Domingos, que os sujeitos indígenas para permanecerem nessa escola, modelada pelas matrizes de conhecimentos abissais (SANTOS, 2010), têm que silenciar a sua cultura e/ou, muitas vezes, negá-la, do contrário, continuam invisíveis, inferiorizados, humilhados até desistirem e evadirem-se para não mais voltar.

\section{REFERÊNCIAS}

BAUMAN, Zygmunt. Identidade: entrevista a Benedetto Vecchi. Rio de Janeiro: Jorge Zahar, 2005.

BANIWA, Gersem. Língua, educação e interculturalidade na perspectiva indígena. In: ALBUQUERQUE, Gerson Rodrigues (Org.). Das margens. Rio Branco: Nepan Editora, 2016. p. 41-56.

BARROS, Josenir Almeida; LIMA, Sandra Cristina Fagundes de. História das escolas públicas primárias em áreas rurais: ausência de políticas públicas (Minas Gerais - 18991911). Revista Histedbr (on line), n.50 (especial), p. 251-263, mai./2013. Disponível: https://periodicos.sbu.unicamp.br/ojs/index.php/histedbr/issue/view/688. Acesso em: 20 jul. 2020.

CANDAU, Vera Maria. Sociedade multicultural e educação: tensões e desafios. In:

CANDAU, Vera Maria (Org.). Didática crítica intercultural: aproximações. Petrópolis-RJ: Vozes, 2012. p. 19-54.

CANDAU, Vera Maria Ferrão F. Educación intercultural crítica: construyendo caminhos. In: WALSH, Catherine (Ed.). Pedagogías decoloniales. Prácticas insurgentes de resistir, (re)existir y (re)vivir. Tomo I. Serie pensamento decolonial. Quito-Ecuador, Ediciones AbyaYala, 2013. p. 145-161.

CAVALCANTI, Marilda do Couto. Estudos sobre educação bilíngue e escolarização em contextos de minorias linguísticas no Brasil. Revista Delta, v. 15, n. esp., p. 385-417, 1999. Disponível em: https://www.scielo.br/pdf/delta/v15nspe/4023.pdf. Acesso em: 10 jul. 2020. FERNANDES, Marilene Alves; CAMARGO, Leila Maria. Magistério indígena tamî’kan: aspectos formativos e desafios curriculares para formação de formadores e professores indígenas-RR. Revista e-Curriculum, São Paulo, v. 18, n. 2, p. 847-865, abr./jun. 2020. Disponívem em: https://revistas.pucsp.br/index.php/curriculum/issue/view/2422. Acesso em: 10 jul. 2020.

FREIRE, José Ribamar Bessa. Rio Babel: a história das línguas na Amazônia. Rio de Janeiro: Atlântica, 2004. 
GOODY, Jack. A domesticação da mente selvagem. Petrópolis, RJ: Vozes, 2012.

ORTIGÃO, Elisa Ramalho. Congo do Espírito Santo: a experiência tradicional como resistência. In: PESSOA, Valda Inês Fontenele; SANTOS, Zuila Guimarães Cova dos (Orgs.). Identidades: culturas, currículos e margens. Curitiba, CRV, 2018. p. 141-154.

POSSENTI, Sírio. Questões para analistas do Discurso. São Paulo: Parábola Editorial, 2009.

SANTOS, Boaventura de Sousa. Crítica da razão indolente: contra o desperdício da experiência. 3. ed., São Paulo: Cortez, 2001.

SANTOS, Boaventura de Sousa. Um discurso sobre as ciências. São Paulo, Cortez, 2009.

SANTOS, Boaventura de Sousa. Para além do pensamento abissal: das linhas globais a uma ecologia de saberes. In: SANTOS, Boaventura de Sousa; MENESES, Maria Paula (Orgs.). Epistemologias do sul. São Paulo: Cortez, 2010. p. 23-71.

SOUZA, Rafael Castro de. A vida sensível do mito na literatura Huni Kuin. Belo Horizonte, UFMG, 2017.

SUSSEKIND, Maria Luiza. A BNCC e o "novo" Ensino Médio: reformas arrogantes, indolentes e malévolas. Retratos da escola, v. 13, n. 25, 2019. Disponível em:

http://retratosdaescola.emnuvens.com.br/rde/article/view/980/pdf\#. Acesso em: 03 ago. 2020.

VEIGA-NETO, Alfredo. Foucault e a Educação. Belo Horizonte: Autêntica, 2003.

WEBER, Ingrid. Um copo de cultura: Os Huni Kuin (Kaxinawá) do Rio Humaitá e a escola. Rio Branco, AC: EDUFAC, 2006.

WALSH, Catherine. Introducción lo pedagógico y lo decolonial: entretejiendo caminos. In:

WALSH, Cathrine (Ed.). Pedagogías Decoloniales. Prácticas insurgentes de resistir, (re)existir y (re)vivir. Tomo I. Serie Pensamiento decolonial. Quito-Ecuador: Ediciones AbyaYala, 2013. p. 23-68.

Recebido em: 13/08/2020

Aprovado em: 13/11/2020 